\title{
RESEARCH
}

Open Access

\section{Cause of death coding in Switzerland: evaluation based on a nationwide individual linkage of mortality and hospital in-patient records}

Ueli Zellweger ${ }^{1}$, Christoph Junker ${ }^{2}$, Matthias Bopp ${ }^{1 *}$ (i) and for the Swiss National Cohort Study Group

\begin{abstract}
Background: Cause of death statistics are an important tool for quality control of the health care system. Their reliability, however, is controversial. Comparing death certificates with their corresponding medical records is implemented only occasionally but may point to quality problems. We aimed at exploring the agreement between information in the cause of death statistics and hospital discharge diagnoses at death.

Methods: Selection of disease categories was based on ICD-10 Tabulation List for Morbidity and ICD-10 Mortality Tabulation List 2. Index cases were defined as deaths having occurred among Swiss residents 2010-2012 in a hospital and successfully linked to the Swiss National Cohort. Rare, external and ill-defined causes were excluded from comparison, leaving 53,605 deaths from vital statistics and 47,311 deaths from hospital discharge statistics. For 95\% of individuals, respective information from the 2000 census could be retrieved and used for multiple logistic regression.
\end{abstract}

Results: For $83 \%$ of individuals the underlying cause of death could be traced among hospital diagnoses and for $77 \%$ the principal hospital diagnosis among the cause of death information. Mirroring different evaluation of complex situations by individual physicians, rates of agreement varied widely depending on disease/cause of death, but were generally in line with similar studies. Multiple logistic regression revealed however significant variation in reporting that could not entirely be explained by age or cause of death of the deceased suggesting differential exploitation of available diagnosis information.

Conclusion: Substantial regional variation and lower agreement rates among socially disadvantaged groups like single, less educated, or culturally less integrated persons suggest potential for improving reporting of diagnoses and causes of death by physicians in Switzerland. Studies of this kind should be regularly conducted as a quality monitoring.

Keywords: Cause of death, Death certificate, Hospital discharge diagnosis, Medical record linkage, Quality monitoring, Switzerland, Validity

\footnotetext{
* Correspondence: Matthias.Bopp@uzh.ch

${ }^{1}$ Epidemiology, Biostatistics and Prevention Institute, University of Zurich,

Hirschengraben 84, CH-8001 Zürich, Switzerland

Full list of author information is available at the end of the article
}

(c) The Author(s). 2019 Open Access This article is distributed under the terms of the Creative Commons Attribution 4.0 International License (http://creativecommons.org/licenses/by/4.0/), which permits unrestricted use, distribution, and reproduction in any medium, provided you give appropriate credit to the original author(s) and the source, provide a link to the Creative Commons license, and indicate if changes were made. The Creative Commons Public Domain Dedication waiver (http://creativecommons.org/publicdomain/zero/1.0/) applies to the data made available in this article, unless otherwise stated. 


\section{Introduction}

Cause of death statistics are an important tool for monitoring the health of populations and for responding effectively to changing epidemiological circumstances [1, 2]. They are also a tool for quality control of the health care system. For example deaths due to causes that should not be fatal in the presence of effective medical care, known as amenable mortality, is an indicator of national levels of personal health-care access and quality [3]. Because of the long-standing supervision by WHO the statistics are, in principle, comparable over time and between countries [4]. Their reliability, however, is controversial [5-7]. Substantial variation in certification practices between countries is a known problem [8,9]. Even within the same country, "different coding practices, socio-cultural milieus, and individual socio-demographic characteristics such as age are most likely to influence the cause of death assigned on the death certificate" [10].

For these reasons it is important to evaluate the reliability of cause-of-death assignment and coding. Usually validation consists in obtaining the coding of the same set of death certificates from different raters $[1,7,10$, 11]. Unfortunately an agreement between the original and the reviewed data may us tell more about reproducibility and less aboutaccuracy of the information [12]. The forms look correct but do not provide an accurate description of the case [13]: Less frequently, death certificates were compared with their corresponding medical records (e.g., $[14,15])$, a procedure rated as too slow and expensive for routine use [13] and therefore implemented only occasionally and studies spanning short periods [15-17]. One of these studies, however, confirmed that medical incompatibility between underlying cause of death and main hospital discharge condition is a marker for greater risk of erroneous cause-of-death certification [16].

Switzerland introduced cause of death statistics in 1876. Certifying by a physician became mandatory a few years later [18]. In the assessments by WHO, the quality of Swiss data was rated as medium [19] or medium-high [5], due to a high proportion of ill-defined causes. This is in line with a recent evaluation by the Global Burden of Disease 2016 Causes of Death Collaborators, which concluded that in Switzerland since 2000 a larger proportion of "well certified deaths" than in neighboring Germany and France (but still not reaching the proportions in neighboring Austria and Italy) [20]. The only evaluation studies comparing cause of death statistics with other medical information date from the 1980s [21, 22]. More recent validation studies were restricted to death certificates and the implications of the adoption of ICD-10 in 1995, trying to identify correction factors with which to correct time series [23, 24].
In Swiss hospitals, cause of death reporting to the Federal Statistical Office is generally in the charge of the responsible attending physician, who also completes the medical files which in turn serve as the basis for the standardized registration of diseases and treatments in the hospital discharge statistics. It is therefore compelling to analyze the consistency of ICD mapping on death certificates and in hospital discharge statistics. Agreement of both, however, is still more a marker for reproducibility than validity of the information. Nevertheless, incompatibility of diagnoses and causes of death may point to quality problems [14].

In contrast to others we did not target an overall quality measure for hospital and cause of death statistics in Switzerland (e.g., the proportion of ill-defined causes) but aimed at assessing the reliability of as many as possible specified diagnoses / causes of death. Within this frame, we first aim at exploring to what extent the underlying cause of death in the cause of death statistics is in agreement with principal and additional diagnoses registered at hospital discharge in the Medical Statistics of Swiss Hospitals (MS). Second, we aim at exploring the opposite, i.e., the agreement of principal diagnosis at hospital discharge with cause of death information on the death certificate. Which causes of death can be traced in the MS especially well or badly and which principal hospital diagnoses can be traced in the cause of death statistics especially well or poorly? In addition, it may be of interest to know which diseases have the most similarity or variation of agreement rates between the two approaches. Finally, we aimed at evaluating combined vs. separate disease categories where the related ICD-codes may not always be easily distinguishable, and at looking for sociodemographic determinants that could influence the agreement between hospital and cause of death data.

For all analyses comparing hospital discharge diagnoses with cause of death information, one has, however, to be aware that the definitions of principal hospital diagnosis and underlying cause of death do not necessarily agree. Cause of death statistics have to deliver a unicausal result, also for multimorbid subjects for whom this concept is not appropriate. On the other hand, medical coding in hospitals first of all serves reimbursement and this may result in distortions [12]. The principal hospital diagnosis may also be a complication of the underlying cause of death. For these reasons, taking into account additional diagnoses as well as concomitant causes of death will be essential.

\section{Methods \\ Data \\ Cause of death statistics}

In Switzerland, death has to be certified by a physician, who can report the immediate and the underlying cause 
of death as well as up to two secondary causes, generally referring to concomitant diseases. The underlying cause of death is defined as a) "the disease or injury which initiated the train of events leading directly to death" or (b) "the circumstances of the accident or violence which produced the fatal injury" [25].

After possible inquiries with the certifying physician, the Swiss Federal Statistical Office centrally codes all cause of death information according to the International Statistical Classification of Diseases and Related Health Problems (ICD-10) and assigns a primary, so-called "definitive" cause of death, which being in most cases identical with the underlying cause on the death certificate - is decisive for all official publications.

For those who died between 55 and 94 years of age, the probability that more than one cause of death is reported as well as the average number of reported causes/diseases gradually increase and only slightly decrease thereafter. In the average, those deceased in a hospital get more diagnoses than those deceased in a long-term care facility, while those deceased at other places (mostly private home) get the fewest diagnoses listed. Restricted to natural deaths in the age span between 60 and 84, men in the average get slightly more diagnoses than women of the same age.

\section{Medical statistics of Swiss hospitals (MS)}

Since 1998 all hospitals in Switzerland have to report their inpatient stays to the Swiss Federal Statistical Office [26]. For every hospital discharge, one principal diagnosis (defined as main reason for medical service or disease having caused most expenditure during this hospital stay) and up to 49 additional diagnoses (previously known or detected during hospitalization) were coded according to the International Statistical Classification of Diseases and Related Health Problems (ICD-10).

In contrast to cause of death statistics, ICD coding as well as an anonymous encryption of the personal identifier is conducted on-site by the hospitals, precluding further inquiries by the Federal Statistical Office [27].

Though this procedure is fully anonymized, hospitalizations of the same individual can be aggregated. Sociodemographic information in the MS is limited to gender, age class and region of residence and there is no established link to the cause of death statistics. Only for decedents, hospitals are obliged to report full date of birth. Using full date of birth, sex, and a geographical identifyer, an anonymous record linkage with the Swiss National Cohort [28] could be successfully established [29], providing additional socio-demographic information (educational level, place of birth, principal language, household type) from the 2000 census for $95 \%$ of deceased individuals in the study population.

\section{Disease categories}

In hospitals, external causes are generally coded within the chapter "Injury, poisoning and certain other consequences of external causes" (S00-T98) rather than the chapter "External causes of morbidity and mortality" (X00-Y99) which is relevant to mortality statistics. In these cases, as well as in the chapter "Symptoms, signs and abnormal clinical and laboratory findings" (R00-R99), an agreement between hospital discharge and mortality statistics a priori cannot be expected and we therefore did not consider external causes.

Selection of categories for analysis and the tables in the results section was based on

1) ICD-10 Tabulation List for Morbidity [25] (A00Q99: 266 of originally 298 items)

2) ICD-10 Mortality Tabulation List 2: General mortality - Selected list [25] (A00-Q99: 69 of originally 80 items)

For the selection of categories we eliminated duplicates and excluded nonspecific ("other...") categories and those with fewer than 30 deaths in 2010-2012 (in both, "definitive" cause of death ${ }^{1}$ and principal hospital discharge diagnosis ${ }^{2}$ ).

Generally, the list for morbidity is more specific than the selected list for mortality. However there are two exceptions (Malignant neoplasm of ovary, C56; Multiple myeloma and malignant plasma cell neoplasms, C90) which were preferred over the corresponding categories in the list for morbidity. Dementia (F01-03) and Alzheimer's disease (G30) were combined into one category, since in every day practice this differentiation is not reliable [30]. Similarly, we put emphasis on keeping the summary as well as the detailed categories for diseases with internationally well-known differentiation problems, i.e. malignancies of the colorectum (C18-C21), coronary heart disease (I20-I25), cerebrovascular diseases (I60-I69) and liver disease (K70-K76). Consequently, we added a respective summary category for malignant uterine tumors (C53-C55). After these modifications, 76 disease master categories (64 from the Tabulation List for Morbidity, 10 from the Mortality Tabulation List, and the two extra items "dementia/Alzheimer's disease" and "all malignant uterine tumors") remained for more thorough analysis.

\section{Statistical analysis}

First, we assessed among those deceased in a hospital to what extent the "definitive" cause of death assigned by the Swiss Federal Statistical Office was in agreement with a) the principal, and b) any hospital discharge diagnosis.

Second, we assessed among the same study population to what extent the principal hospital discharge diagnosis 
was in agreement with underlying, immediate and contributory causes of death recorded.

SPSS 25 (IBM Corp, 2017) was used to calculate proportions of decedents who had a) the "definitive" underlying cause of death also as the principal or an additional discharge diagnosis for their terminal hospital stay, and b) who had the principal hospital discharge diagnosis also registered as the underlying or a contributory cause of death in the mortality statistics. Agreement between hospital diagnoses and causes of death was measured by kappa coefficients using SPSS 25. Logistic regression was performed using STATA 13.1 (StataCorp, 2013) to assess the influence of socio-demographic variables on the agreement of hospital diagnoses and the underlying cause of death.

\section{Results}

\section{Study population}

Index cases were defined as deaths having occurred among Swiss residents 2010-2012 in a hospital and successfully linked to a cause of death statistics record. Starting with 74,093 deaths registered in the hospital discharge statistics, 72,566 were found to be index cases (97.9\%) (Fig. 1). Among those, 1050 cases had no or exclusively "Z"-diagnoses ("Factors influencing health status and contact with health services") and were excluded from analyses. The final number of valid cases is therefore 71,516.

Excluding external and ill-defined causes, tracing causes of death in the hospital discharge statistics was restricted to those with a "definitive" cause of death in the range A00-Q99 $(N=66,424)$, and tracing diagnoses in the cause of death statistics to those with a principal hospital discharge diagnosis in the range A00-Q99 $(N=62,628)$.

Overall, 5.3\% (men) and 5.8\% (women) had only one i.e., the principal - diagnosis. On average, 8.1 (men) and 7.6 (women) diagnoses were reported, with a maximum of almost 11 among boys aged $10-14$ years and a minimum of 5.8 among women aged 95 years and more.

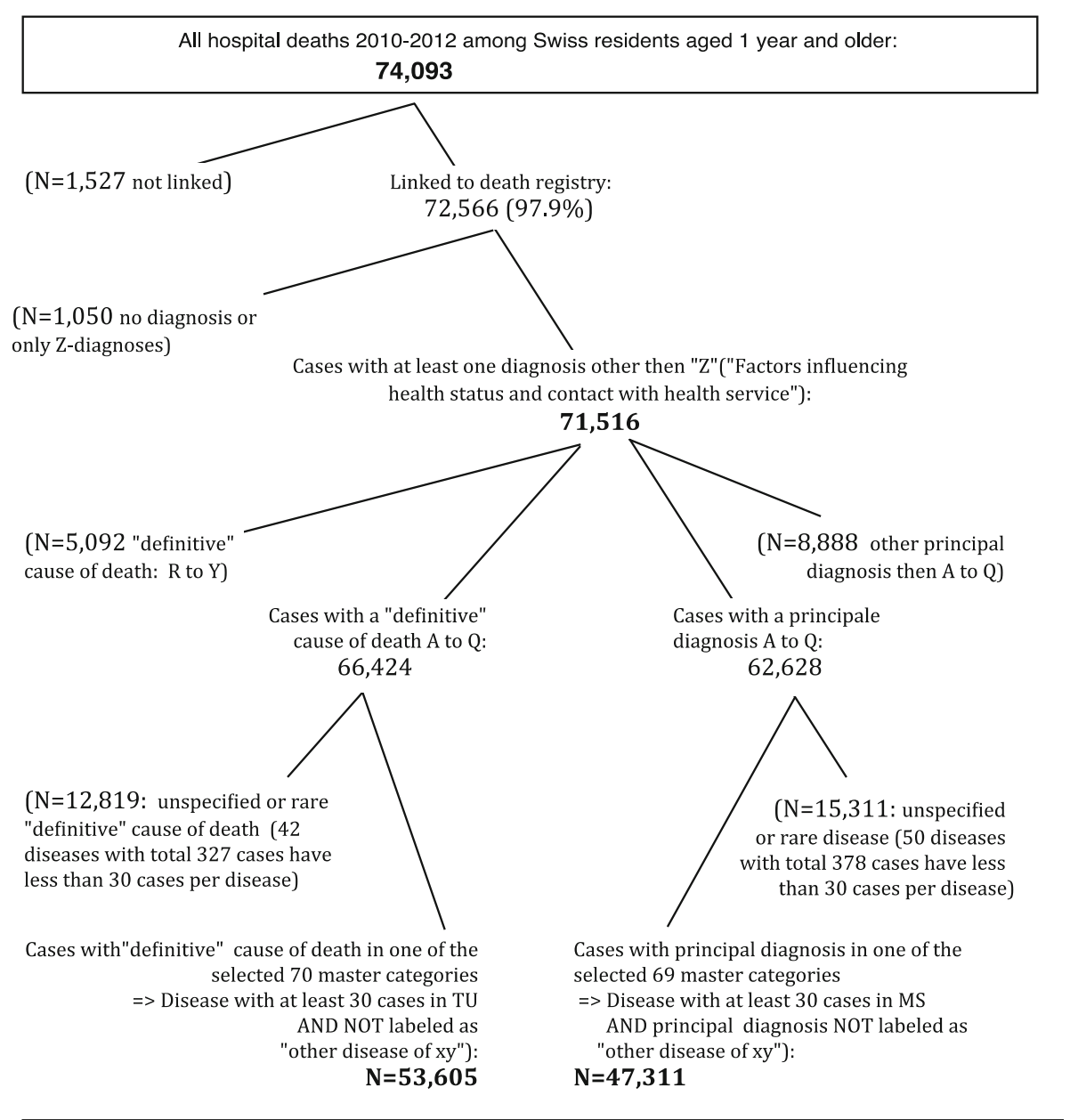

Fig. 1 Derivation of the study population. Hospital deaths 2010-2012 among Swiss residents aged 1 year and older, which could be linked to the death registry and categorized into one of 70 master categories of cause of death or into one of 69 master categories of principal hospital discharge diagnosis 
With focus on tracing cause of death in hospital diagnoses, analyses encompassed 53,605 deaths in 70 master categories, whereas for tracing the principal diagnosis in cause of death information, there were 47,311 deaths in 69 master categories (with 64 of these master categories being identical - see footnote above). From the overall 76 disease master categories, 9 were divided into overall 21 subcategories, inducing a final tabulation set of 97 disease categories.

"Definitive" underlying cause of death found in diagnoses of the terminal hospital discharge record

Among the 70 selected master categories, for $83 \%$ $(44,740 / 53,605)$ of cases the individual "definitive" underlying cause of death could be found among the principal or additional diagnoses reported for the terminal hospital stay of the same individual.

For most categories, in at least $70 \%$ of cases the underlying cause of death was also reported in the Medical Statistics of the Swiss Hospitals (Table 1). For cancer categories this proportion was generally over $80 \%$. The largest agreements were observed for diseases of the liver (93\%), multiple myeloma, lung and brain cancer (all $92 \%$ ), diseases of the pancreas (91\%), renal failure, breast and pancreatic cancer (all 90\%), and cerebrovascular diseases $(89 \%)$.

Low agreement was observed for not specified stroke (22\%) and other cerebrovascular diseases (31\%), arthrosis and chronic rheumatic heart disease (both 36\%), diarrhoea/ gastro-enteritis (38\%), and primary hypertension (40\%).

Using the kappa coefficient, the variation between cancer categories (kappa generally $>0.70$, the highest values were obtained for pancreatic cancer, kappa $=0.91$, and brain cancer, kappa $=0.90$ ) and the other diseases (kappa generally < 0.30 ) became even more apparent: notable exceptions were only cerebrovascular diseases $(k a p p a=$ $0.63)$, multiple sclerosis (kappa $=0.60)$, AMI and alcoholic liver disease (both kappa $=0.59$ ).

Based on the proportion of agreement the following master categories substantially outperformed the respective subcategories: cerebrovascular diseases, hypertensive diseases, liver disease and Alzheimer's disease/ other dementia. Also for colorectal and uterine cancer the master category performed better than the subcategories, whereas for chronic lower respiratory diseases vs. COPD, ischaemic heart diseases vs. AMI and mental disorders due to substance abuse this was not the case. Based on the kappa coefficient, only the colorectal and uterine cancer master categories had an unambiguous advantage over the respective subcategories.

Restricted to the principal hospital discharge diagnosis, agreement with the "definitive" underlying cause of death decreased to $50 \%$, with most distinctive decreases for multiple sclerosis (found in $86 \%$ of linked hospital discharge records, but only in $14 \%$ as the principal diagnosis), diabetes mellitus (78 -->13\%), hypertensive diseases (69 -- >5\%), mental disorders due to alcohol use (78 -- >15\%), cerebral palsy (74 -->11\%), Parkinson's disease (75 -- > 19\%), Alzheimer's disease/other dementia (73 -- > 19\%), HIV disease (83 -- > 31\%), chronic lower respiratory diseases $(84 \quad->32 \%)$, and renal failure (90 -- > 40\%).

\section{Principal hospital discharge diagnosis found in cause of death statistics}

Among the 69 selected master categories, for $77 \%$ $(36,456 / 47,311)$ of cases the principal diagnosis at the terminal hospital stay could be traced among the cause of death information for the respective individual. Rates of agreement were highest for cancers (with up to $98 \%$ for breast cancer, $97 \%$ for prostate cancer and multiple myeloma, 96\% for melanoma of skin and lung cancer, 93\% for cerebrovascular diseases, 92\% for multiple sclerosis and ischaemic heart diseases, and $90 \%$ for chronic lower respiratory disease and liver disease (Table 2).

Again, using the kappa coefficient, the variation between cancer categories (kappa generally $\geq 0.59$, maxima in brain cancer, kappa $=0.82$, and pancreatic cancer, kappa $=0.77$ ) and the other diseases (kappa generally< 0.30 ) is obvious, however less distinct than in the first analysis. Notable exceptions from the generally low kappa values were only cerebrovascular diseases (kappa $=0.69)$ and AMI (kappa $=0.62)$.

As to the proportion of agreement, the master categories cerebrovascular diseases, ischaemic heart diseases and Alzheimer's disease/other dementia substantially outperformed the respective subcategories, but also in liver disease and colorectal cancer the master categories performed clearly better than the average of the respective subcategories. Based on the kappa coefficient the advantage of the master category was limited to colorectal cancer.

Restricted to the "definitive" underlying cause of death, agreement with principal hospital discharge diagnosis decreased to $57 \%$, with most distinctive decreases for pneumonia (69 -- > 22\%), renal failure (68 -- > 23\%), pulmonary embolism (80 -- > 36\%), septicaemia (49 -- >7\%), cardiac arrhythmias (58 -- > 16\%) and heart failure (53 -- > 14\%).

Agreement between principal hospital discharge diagnosis and the original underlying cause of death was even slightly lower $(54 \% ; 25,762 / 47,311)$, with some exceptions from this general pattern (most notably atherosclerosis, hypertensive diseases, pneumonia, liver disease and mental disorders due to alcohol use).

\section{Determinants of agreement between hospital and death records}

For men and even more for women deceased after age 60 , agreement of the "definitive" cause of death with any 
Table 1 Agreement of underlying cause of death with diagnoses registered for the terminal hospitalization

\begin{tabular}{|c|c|c|c|c|c|}
\hline \multirow[t]{2}{*}{ "Definitive" cause of death } & \multirow{2}{*}{$\begin{array}{l}\text { Ind as ... } \\
\mathrm{N}\end{array}$} & \multirow{2}{*}{$\frac{\text { Principal diagnosis }}{\%}$} & \multicolumn{3}{|c|}{ In any diagnosis } \\
\hline & & & $\mathrm{N}$ & $\%$ & Kappa \\
\hline \multicolumn{6}{|c|}{ Chapter 1: A00-B99 Certain infectious and parasitic diseases } \\
\hline Diarrhoea / gastro-enteritis of presumed infectious origin & 109 & $17 \%$ & 41 & $38 \%$ & 0.12 \\
\hline Septicaemia & 503 & $63 \%$ & 383 & $76 \%$ & 0.08 \\
\hline Human immunodeficiency virus [HIV] disease & 84 & $31 \%$ & 70 & $83 \%$ & 0.60 \\
\hline Mycoses & 30 & $47 \%$ & 26 & $87 \%$ & 0.02 \\
\hline \multicolumn{6}{|c|}{ Chapter 2: C00-D49 Neoplasms } \\
\hline Malignant neoplasm of lip, oral cavity / pharynx & 727 & $59 \%$ & 607 & $83 \%$ & 0.82 \\
\hline Malignant neoplasm of oesophagus & 825 & $57 \%$ & 726 & $88 \%$ & 0.86 \\
\hline Malignant neoplasm of stomach & 910 & $64 \%$ & 793 & $87 \%$ & 0.85 \\
\hline Malignant neoplasm of colon, rectum / anus & 2917 & $58 \%$ & 2578 & $88 \%$ & 0.87 \\
\hline Malignant neoplasm of colon & 1939 & $55 \%$ & 1607 & $83 \%$ & 0.83 \\
\hline Malignant neoplasm of rectosigmoid junction, rectum, anus / anal canal & 978 & $53 \%$ & 809 & $83 \%$ & 0.79 \\
\hline Malignant neoplasm of liver / intrahepatic bile ducts & 1252 & $57 \%$ & 1025 & $82 \%$ & 0.81 \\
\hline Malignant neoplasm of pancreas & 2019 & $68 \%$ & 1826 & $90 \%$ & 0.91 \\
\hline Malignant neoplasm of larynx & 137 & $51 \%$ & 103 & $75 \%$ & 0.71 \\
\hline Malignant neoplasm of trachea, bronchus / lung & 5825 & $62 \%$ & 5359 & $92 \%$ & 0.91 \\
\hline Malignant neoplasm of bone / articular cartilage & 59 & $46 \%$ & 40 & $68 \%$ & 0.54 \\
\hline Malignant melanoma of skin & 505 & $44 \%$ & 402 & $80 \%$ & 0.85 \\
\hline Malignant neoplasms of mesothelial / soft tissue & 599 & $55 \%$ & 469 & $78 \%$ & 0.76 \\
\hline Malignant neoplasm of breast & 2226 & $51 \%$ & 2013 & $90 \%$ & 0.88 \\
\hline Malignant neoplasm of cervix uteri / uterus & 470 & $55 \%$ & 392 & $83 \%$ & 0.83 \\
\hline Malignant neoplasm of cervix uteri & 133 & $57 \%$ & 107 & $80 \%$ & 0.81 \\
\hline Malignant neoplasm of other / unspecified parts of uterus & 337 & $51 \%$ & 271 & $80 \%$ & 0.80 \\
\hline Malignant neoplasm of ovary & 766 & $54 \%$ & 658 & $86 \%$ & 0.88 \\
\hline Malignant neoplasm of prostate & 1751 & $47 \%$ & 1559 & $89 \%$ & 0.79 \\
\hline Malignant neoplasm of bladder & 873 & $50 \%$ & 700 & $80 \%$ & 0.75 \\
\hline Malignant neoplasm of eye / adnexa & 48 & $40 \%$ & 35 & $73 \%$ & 0.74 \\
\hline Malignant neoplasm of brain & 671 & $75 \%$ & 615 & $92 \%$ & 0.90 \\
\hline Hodgkin's disease & 60 & $43 \%$ & 44 & $73 \%$ & 0.66 \\
\hline Non-Hodgkin's lymphoma & 934 & $56 \%$ & 799 & $86 \%$ & 0.81 \\
\hline Multiple myeloma / malignant plasma cell neoplasms & 555 & $58 \%$ & 513 & $92 \%$ & 0.86 \\
\hline Leukaemia & 1116 & $56 \%$ & 961 & $86 \%$ & 0.80 \\
\hline
\end{tabular}

Chapter 3:D50-D89 Diseases of the blood and blood-forming organs / certain disorders involving the immune mechanism

\begin{tabular}{|c|c|c|c|c|c|}
\hline Anaemias & 136 & $36 \%$ & 104 & $76 \%$ & 0.01 \\
\hline Haemorrhagic conditions / other diseases of blood (-forming organs) & 74 & $35 \%$ & 59 & $80 \%$ & 0.02 \\
\hline \multicolumn{6}{|c|}{ Chapter 4: E00-E89 Endocrine, nutritional and metabolic diseases } \\
\hline Diabetes mellitus & 657 & $13 \%$ & 511 & $78 \%$ & 0.08 \\
\hline Obesity & 61 & $16 \%$ & 42 & $69 \%$ & 0.06 \\
\hline \multicolumn{6}{|c|}{ Chapter 5: F01-F99 Mental, Behavioral and Neurodevelopmental disorders } \\
\hline Mental / behavioural disorders due to psychoactive substance use & 121 & $11 \%$ & 93 & $77 \%$ & 0.05 \\
\hline Mental / behavioural disorders due to use of alcohol & 85 & $15 \%$ & 66 & $78 \%$ & 0.07 \\
\hline Mental / behavioural disorders due to other psychoactive substance use & 36 & $0 \%$ & 25 & $69 \%$ & 0.03 \\
\hline Schizophrenia, schizotypal / delusional disorders & 41 & $56 \%$ & 34 & $83 \%$ & 0.14 \\
\hline
\end{tabular}


Table 1 Agreement of underlying cause of death with diagnoses registered for the terminal hospitalization (Continued)

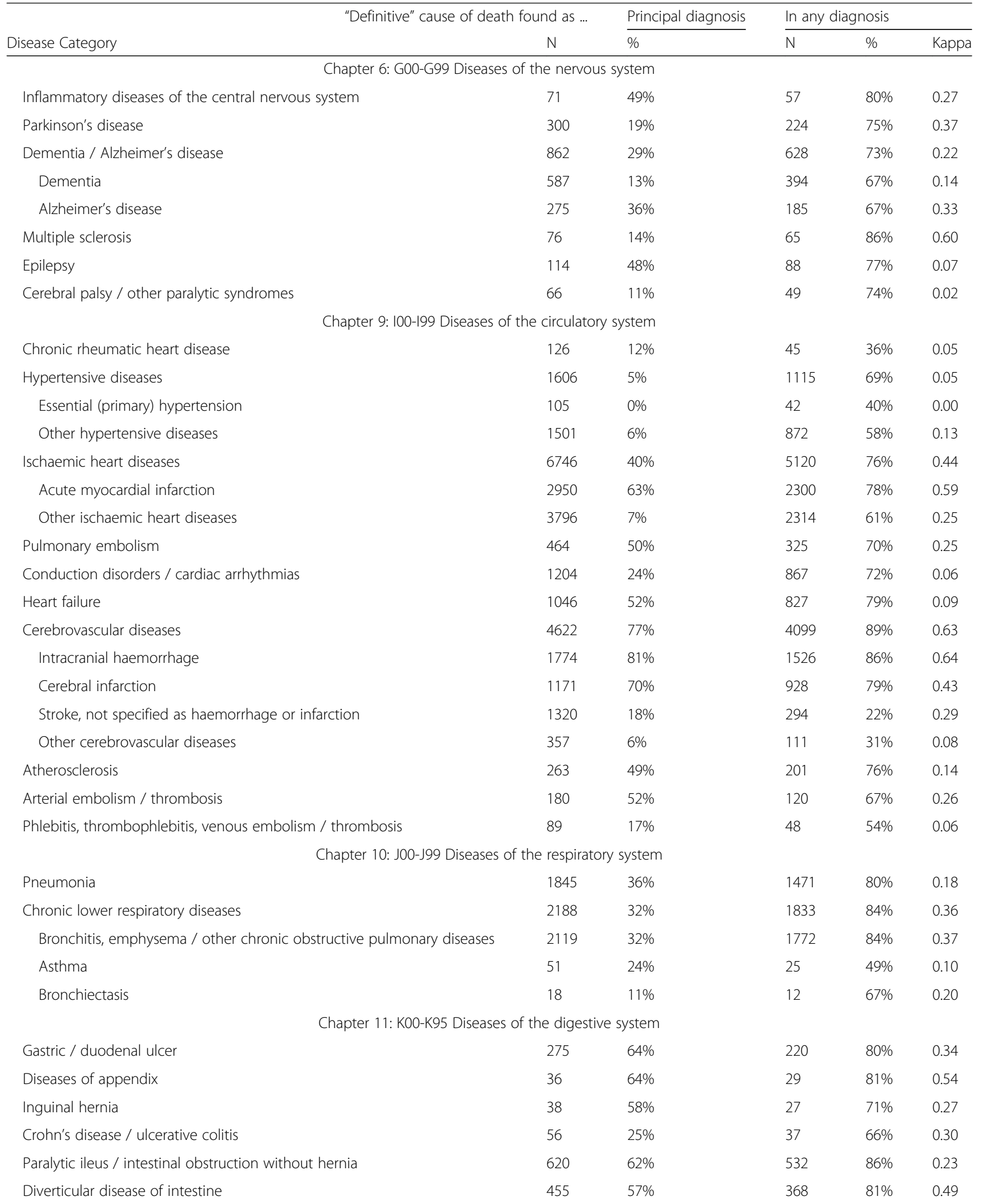


Table 1 Agreement of underlying cause of death with diagnoses registered for the terminal hospitalization (Continued)

\begin{tabular}{|c|c|c|c|c|c|}
\hline \multirow[b]{2}{*}{ Disease Category } & \multirow{2}{*}{$\begin{array}{l}\text { nd as ... } \\
\mathrm{N}\end{array}$} & \multirow{2}{*}{$\frac{\text { Principal diagnosis }}{\%}$} & \multicolumn{3}{|c|}{ In any diagnosis } \\
\hline & & & N & $\%$ & Kappa \\
\hline Diseases of the liver & 1367 & $54 \%$ & 1269 & $93 \%$ & 0.36 \\
\hline Alcoholic liver disease & 1009 & $44 \%$ & 808 & $80 \%$ & 0.59 \\
\hline Other diseases of liver & 358 & $43 \%$ & 303 & $85 \%$ & 0.12 \\
\hline Cholelithiasis / cholecystitis & 249 & $45 \%$ & 216 & $87 \%$ & 0.40 \\
\hline Acute pancreatitis / other diseases of the pancreas & 211 & $60 \%$ & 192 & $91 \%$ & 0.47 \\
\hline \multicolumn{6}{|c|}{ Chapter 12: L00-L99 Diseases of the skin and subcutaneous tissue } \\
\hline Infections of the skin / subcutaneous tissue & 70 & $23 \%$ & 40 & $57 \%$ & 0.13 \\
\hline \multicolumn{6}{|c|}{ Chapter 13: M00-M99 Diseases of the musculoskeletal system / connective tissue } \\
\hline Rheumatoid arthritis / other inflammatory polyarthropathies & 66 & $17 \%$ & 52 & $79 \%$ & 0.10 \\
\hline Arthrosis & 114 & $27 \%$ & 41 & $36 \%$ & 0.10 \\
\hline Systemic connective tissue disorders & 139 & $29 \%$ & 100 & $72 \%$ & 0.26 \\
\hline Soft tissue disorders & 55 & $36 \%$ & 41 & $75 \%$ & 0.06 \\
\hline Disorders of bone density / structure & 35 & $34 \%$ & 20 & $57 \%$ & 0.02 \\
\hline Osteomyelitis & 32 & $16 \%$ & 22 & $69 \%$ & 0.15 \\
\hline \multicolumn{6}{|c|}{ Chapter 14: N00-N99 Diseases of the genitourinary system } \\
\hline Renal tubulo-interstitial diseases & 70 & $20 \%$ & 48 & $69 \%$ & 0.09 \\
\hline Renal failure & 687 & $40 \%$ & 617 & $90 \%$ & 0.04 \\
\hline Hyperplasia of prostate & 35 & $11 \%$ & 17 & $49 \%$ & 0.03 \\
\hline \multicolumn{6}{|c|}{ Chapter 17: Q00-Q99 Congenital malformations, deformations and chromosomal abnormalities } \\
\hline Congenital malformations of the circulatory system & 66 & $11 \%$ & 32 & $48 \%$ & 0.26 \\
\hline Total Cases (sum of 70 master categories) & 53,605 & $50 \%$ & 44,740 & $83 \%$ & \\
\hline
\end{tabular}

hospital diagnosis decreased with increasing age from around $90 \%$ to around $75 \%$ among those aged 90 years and more (Fig. 2a). This decrease is almost entirely due to decreasing agreement with principal hospital discharge diagnosis, while agreement with additional hospital diagnoses varied only slightly (between 29 and $35 \%)$.

The agreement of principal hospital diagnosis with cause of death information decreases with increasing age, too (Fig. 2b). Proportions of agreement however are lower and the general decrease applies to both, "definitive" and additional causes of death.

\section{Socio-demographic determinants for individual level disagreement}

For 50,995 of the 53,605 deceased persons with a "definitive" cause of death classified in one of the 70 master categories (95.1\%), socio-demographic information from the 2000 census could be retrieved. Multiple logistic regression revealed substantial impact of socio-demographic determinants on agreement of "definitive" cause of death and any hospital discharge diagnoses. Compared to the Lake Geneva region, the only predominantly French-speaking region, agreement at the individual level was higher in all parts of Switzerland, most obviously in Zurich $(\mathrm{OR}=1.28 ; 95 \%$ CI 1.15-1.41) and Espace Mittelland $(\mathrm{OR}=1.21 ; 1.11-1.31)$ (Table 3$)$. Higher agreement also applied to ever married individuals and those with a higher educational level, whereas French speaking individuals and even more so those speaking a non-European language had significantly lower odds of agreement than their German speaking counterparts. As in the descriptive analysis, age but not sex of the deceased had substantial impact on the odds of agreement.

Focussing on agreement of "definitive" cause of death and principal hospital discharge diagnosis provided similar however attenuated patterns, with highest agreement in Northwestern Switzerland but no significant variation by language category.

For $95.1 \%(44,993 / 47,311)$ of deceased individuals with a principal diagnosis in one of the 69 master categories, information from the 2000 census could be retrieved. In multiple logistic regression, retrieval in cause of death information were again significantly lower among single and less educated individuals and higher in Northwestern Switzerland, but not among native-speakers of non-Swiss languages (data not shown). 
Table 2 Agreement of principal hospital discharge diagnosis with cause of death statistics

\begin{tabular}{|c|c|c|c|c|c|}
\hline \multirow[b]{2}{*}{ Disease Category } & \multirow{2}{*}{$\begin{array}{l}\text { ind as ... } \\
\mathrm{N}\end{array}$} & \multirow{2}{*}{$\frac{\text { "Definitive" cause of death }}{\%}$} & \multicolumn{3}{|c|}{ In any cause of death } \\
\hline & & & $\mathrm{N}$ & $\%$ & Kappa \\
\hline \multicolumn{6}{|c|}{ Chapter 1: A00-B99 Certain infectious and parasitic diseases } \\
\hline Diarrhoea / gastro-enteritis of presumed infectious origin & 90 & $20 \%$ & 31 & $34 \%$ & 0.18 \\
\hline Septicaemia & 4330 & $7 \%$ & 2108 & $49 \%$ & 0.41 \\
\hline Human immunodeficiency virus [HIV] disease & 30 & $87 \%$ & 27 & $90 \%$ & 0.41 \\
\hline Mycoses & 95 & $15 \%$ & 45 & $47 \%$ & 0.25 \\
\hline \multicolumn{6}{|c|}{ Chapter 2: C00-D49 Neoplasms } \\
\hline Malignant neoplasm of lip, oral cavity / pharynx & 462 & $92 \%$ & 434 & $94 \%$ & 0.65 \\
\hline Malignant neoplasm of oesophagus & 524 & $90 \%$ & 483 & $92 \%$ & 0.68 \\
\hline Malignant neoplasm of stomach & 657 & $88 \%$ & 587 & $89 \%$ & 0.71 \\
\hline Malignant neoplasm of colon, rectum / anus & 1820 & $93 \%$ & 1722 & $95 \%$ & 0.67 \\
\hline Malignant neoplasm of colon & 1187 & $90 \%$ & 1084 & $91 \%$ & 0.64 \\
\hline Malignant neoplasm of rectosigmoid junction, rectum, anus / anal canal & 634 & $82 \%$ & 534 & $84 \%$ & 0.61 \\
\hline Malignant neoplasm of liver / intrahepatic bile ducts & 820 & $87 \%$ & 726 & $89 \%$ & 0.67 \\
\hline Malignant neoplasm of pancreas & 1474 & $93 \%$ & 1384 & $94 \%$ & 0.77 \\
\hline Malignant neoplasm of larynx & 85 & $82 \%$ & 71 & $84 \%$ & 0.49 \\
\hline Malignant neoplasm of trachea, bronchus / lung & 3793 & $95 \%$ & 3644 & $96 \%$ & 0.72 \\
\hline Malignant neoplasm of bone / articular cartilage & 46 & $59 \%$ & 27 & $59 \%$ & 0.49 \\
\hline Malignant melanoma of skin & 235 & $95 \%$ & 225 & $96 \%$ & 0.56 \\
\hline Malignant neoplasms of mesothelial / soft tissue & 387 & $84 \%$ & 330 & $85 \%$ & 0.64 \\
\hline Malignant neoplasm of breast & 1165 & $97 \%$ & 1143 & $98 \%$ & 0.59 \\
\hline Malignant neoplasm of cervix uteri / uterus & 289 & $89 \%$ & 261 & $90 \%$ & 0.63 \\
\hline Malignant neoplasm of cervix uteri & 85 & $89 \%$ & 76 & $89 \%$ & 0.66 \\
\hline Malignant neoplasm of other / unspecified parts of uterus & 204 & $85 \%$ & 177 & $87 \%$ & 0.59 \\
\hline Malignant neoplasm of ovary & 444 & $93 \%$ & 421 & $95 \%$ & 0.66 \\
\hline Malignant neoplasm of prostate & 879 & $94 \%$ & 849 & $97 \%$ & 0.47 \\
\hline Malignant neoplasm of bladder & 529 & $83 \%$ & 455 & $86 \%$ & 0.56 \\
\hline Malignant neoplasm of brain & 543 & $93 \%$ & 504 & $93 \%$ & 0.82 \\
\hline Hodgkin's disease & 35 & $74 \%$ & 26 & $74 \%$ & 0.43 \\
\hline Non-Hodgkin's lymphoma & 589 & $89 \%$ & 539 & $92 \%$ & 0.62 \\
\hline Multiple myeloma / malignant plasma cell neoplasms & 337 & $95 \%$ & 327 & $97 \%$ & 0.65 \\
\hline Leukaemia & 710 & $88 \%$ & 650 & $92 \%$ & 0.62 \\
\hline
\end{tabular}

Chapter 3:D50-D89 Diseases of the blood and blood-forming organs / certain disorders involving the immune mechanism

\begin{tabular}{|c|c|c|c|c|c|}
\hline Anaemias & 202 & $24 \%$ & 101 & $50 \%$ & 0.08 \\
\hline Haemorrhagic conditions / other diseases of blood (-forming organs) & 279 & $9 \%$ & 72 & $26 \%$ & 0.14 \\
\hline \multicolumn{6}{|c|}{ Chapter 4: E00-E89 Endocrine, nutritional and metabolic diseases } \\
\hline Diabetes mellitus & 180 & $46 \%$ & 132 & $73 \%$ & 0.04 \\
\hline Malnutrition & 60 & $10 \%$ & 20 & $33 \%$ & 0.07 \\
\hline Volume depletion & 113 & $4 \%$ & 28 & $25 \%$ & 0.08 \\
\hline \multicolumn{6}{|l|}{ hapter 5: F01-F99 Mental, Behavioral and Neurodevelopmental disorders } \\
\hline Mental / behavioural disorders due to psychoactive substance use & 65 & $20 \%$ & 31 & $48 \%$ & 0.04 \\
\hline Mental / behavioural disorders due to use of alcohol & 45 & $29 \%$ & 21 & $47 \%$ & 0.05 \\
\hline Mental / behavioural disorders due to other psychoactive substance use & 20 & $0 \%$ & 9 & $45 \%$ & 0.03 \\
\hline
\end{tabular}


Table 2 Agreement of principal hospital discharge diagnosis with cause of death statistics (Continued)

\begin{tabular}{|c|c|c|c|c|c|}
\hline \multirow[b]{2}{*}{ Disease Category } & \multirow{2}{*}{$\begin{array}{l}\text { and as ... } \\
\mathrm{N}\end{array}$} & \multirow{2}{*}{$\frac{\text { "Definitive" cause of death }}{\%}$} & \multicolumn{3}{|c|}{ In any cause of death } \\
\hline & & & $\mathrm{N}$ & $\%$ & Kappa \\
\hline Schizophrenia, schizotypal / delusional disorders & 122 & $19 \%$ & 68 & $56 \%$ & 0.36 \\
\hline Mood [affective] disorders & 180 & $7 \%$ & 93 & $52 \%$ & 0.22 \\
\hline Neurotic, stress-related and somatoform disorders & 55 & $2 \%$ & 5 & $9 \%$ & 0.05 \\
\hline \multicolumn{6}{|c|}{ Chapter 6: G00-G99 Diseases of the nervous system } \\
\hline Inflammatory diseases of the central nervous system & 88 & $40 \%$ & 57 & $65 \%$ & 0.46 \\
\hline Parkinson's disease & 73 & $78 \%$ & 66 & $90 \%$ & 0.15 \\
\hline Dementia / Alzheimer's disease & 465 & $54 \%$ & 365 & $78 \%$ & 0.20 \\
\hline Dementia & 229 & $34 \%$ & 146 & $64 \%$ & 0.10 \\
\hline Alzheimer's disease & 236 & $42 \%$ & 118 & $50 \%$ & 0.28 \\
\hline Epilepsy & 296 & $19 \%$ & 159 & $54 \%$ & 0.30 \\
\hline Transient cerebral ischaemic attacks and related syndromes & 34 & $0 \%$ & 3 & $9 \%$ & 0.07 \\
\hline Cerebral palsy / other paralytic syndromes & 78 & $9 \%$ & 20 & $26 \%$ & 0.09 \\
\hline \multicolumn{6}{|c|}{ Chapter 9: 100-199 Diseases of the circulatory system } \\
\hline Chronic rheumatic heart disease & 88 & $17 \%$ & 17 & $19 \%$ & 0.10 \\
\hline Hypertensive diseases & 272 & $31 \%$ & 174 & $64 \%$ & 0.02 \\
\hline Essential (primary) hypertension & 6 & $0 \%$ & 2 & $33 \%$ & 0.00 \\
\hline Other hypertensive diseases & 266 & $32 \%$ & 161 & $61 \%$ & 0.03 \\
\hline Ischaemic heart diseases & 3144 & $85 \%$ & 2890 & $92 \%$ & 0.30 \\
\hline Acute myocardial infarction & 2692 & $68 \%$ & 1980 & $74 \%$ & 0.62 \\
\hline Other ischaemic heart diseases & 452 & $61 \%$ & 365 & $81 \%$ & 0.05 \\
\hline Pulmonary embolism & 648 & $36 \%$ & 521 & $80 \%$ & 0.34 \\
\hline Conduction disorders / cardiac arrhythmias & 1864 & $16 \%$ & 1087 & $58 \%$ & 0.13 \\
\hline Heart failure & 3842 & $14 \%$ & 2043 & $53 \%$ & 0.39 \\
\hline Cerebrovascular diseases & 4829 & $74 \%$ & 4476 & $93 \%$ & 0.69 \\
\hline Intracranial haemorrhage & 2181 & $66 \%$ & 1929 & $88 \%$ & 0.76 \\
\hline Cerebral infarction & 2081 & $40 \%$ & 991 & $48 \%$ & 0.52 \\
\hline Stroke, not specified as haemorrhage or infarction & 460 & $53 \%$ & 312 & $68 \%$ & 0.23 \\
\hline Other cerebrovascular diseases & 141 & $16 \%$ & 54 & $38 \%$ & 0.05 \\
\hline Atherosclerosis & 448 & $29 \%$ & 276 & $62 \%$ & 0.22 \\
\hline Arterial embolism / thrombosis & 282 & $33 \%$ & 136 & $48 \%$ & 0.41 \\
\hline Phlebitis, thrombophlebitis, venous embolism / thrombosis & 70 & $21 \%$ & 35 & $50 \%$ & 0.08 \\
\hline \multicolumn{6}{|c|}{ Chapter 10: J00-J99 Diseases of the respiratory system } \\
\hline Pneumonia & 2926 & $22 \%$ & 2027 & $69 \%$ & 0.32 \\
\hline Chronic lower respiratory diseases & 892 & $78 \%$ & 801 & $90 \%$ & 0.20 \\
\hline Bronchitis, emphysema / other chronic obstructive pulmonary diseases & 868 & $78 \%$ & 773 & $89 \%$ & 0.21 \\
\hline Asthma & 20 & $60 \%$ & 13 & $65 \%$ & 0.07 \\
\hline Bronchiectasis & 5 & $40 \%$ & 2 & $40 \%$ & 0.10 \\
\hline \multicolumn{6}{|c|}{ Chapter 11: K00-K95 Diseases of the digestive system } \\
\hline Gastric / duodenal ulcer & 376 & $47 \%$ & 216 & $57 \%$ & 0.51 \\
\hline Gastritis and duodenitis & 31 & $16 \%$ & 9 & $29 \%$ & 0.15 \\
\hline Diseases of appendix & 33 & $70 \%$ & 24 & $73 \%$ & 0.62 \\
\hline Inguinal hernia & 56 & $39 \%$ & 27 & $48 \%$ & 0.45 \\
\hline Paralytic ileus / intestinal obstruction without hernia & 1092 & $35 \%$ & 746 & $68 \%$ & 0.45 \\
\hline
\end{tabular}


Table 2 Agreement of principal hospital discharge diagnosis with cause of death statistics (Continued)

\begin{tabular}{|c|c|c|c|c|c|}
\hline \multirow[b]{2}{*}{ Disease Category } & \multirow{2}{*}{$\begin{array}{l}\text { Principal diagnosis found as ... } \\
\qquad \mathrm{N}\end{array}$} & \multirow{2}{*}{$\frac{\text { "Definitive" cause of death }}{\%}$} & \multicolumn{3}{|c|}{ In any cause of death } \\
\hline & & & $\mathrm{N}$ & $\%$ & Kappa \\
\hline Diverticular disease of intestine & 429 & $60 \%$ & 300 & $70 \%$ & 0.53 \\
\hline Diseases of the liver & 1161 & $64 \%$ & 1040 & $90 \%$ & 0.40 \\
\hline Alcoholic liver disease & 560 & $79 \%$ & 477 & $85 \%$ & 0.49 \\
\hline Other diseases of liver & 612 & $25 \%$ & 406 & $66 \%$ & 0.23 \\
\hline Cholelithiasis / cholecystitis & 199 & $56 \%$ & 130 & $65 \%$ & 0.44 \\
\hline Acute pancreatitis / other diseases of the pancreas & 179 & $71 \%$ & 158 & $88 \%$ & 0.54 \\
\hline \multicolumn{6}{|c|}{ Chapter 12: L00-L99 Diseases of the skin and subcutaneous tissue } \\
\hline Infections of the skin / subcutaneous tissue & 71 & $23 \%$ & 23 & $32 \%$ & 0.19 \\
\hline \multicolumn{6}{|c|}{ Chapter 13: M00-M99 Diseases of the musculoskeletal system / connective tissue } \\
\hline Arthrosis & 112 & $28 \%$ & 47 & $42 \%$ & 0.21 \\
\hline Systemic connective tissue disorders & 65 & $63 \%$ & 50 & $77 \%$ & 0.21 \\
\hline Soft tissue disorders & 122 & $16 \%$ & 37 & $30 \%$ & 0.19 \\
\hline Disorders of bone density / structure & 94 & $13 \%$ & 33 & $35 \%$ & 0.08 \\
\hline Osteomyelitis & 35 & $14 \%$ & 18 & $51 \%$ & 0.29 \\
\hline \multicolumn{6}{|c|}{ Chapter 14: N00-N99 Diseases of the genitourinary system } \\
\hline Renal tubulo-interstitial diseases & 87 & $16 \%$ & 36 & $41 \%$ & 0.20 \\
\hline Renal failure & 1206 & $23 \%$ & 826 & $68 \%$ & 0.13 \\
\hline Total Cases (sum of 69 master categories) & 47,311 & $57 \%$ & 36,442 & $77 \%$ & \\
\hline
\end{tabular}

\section{Discussion}

In Switzerland, on an individual level cause of death information in official cause of death statistics and diagnoses in the hospital discharge statistics are generally compatible, especially if additional diagnoses and contributory causes are taken into account. In $83 \%$ of analyzed deaths, the underlying cause of death could be traced in one of the diagnoses of the terminal hospital discharge and in $77 \%$ the principal discharge diagnosis was also reported as primary or contributory cause of death (principal diagnosis $=$ primary cause: $57 \%$ ). This is fairly in line with Johansson\&Westerling who found agreement of principal hospital condition with underlying cause of death of $59 \%$ and with any information on the death certificate of $83 \%$ [13]. The latter number is somewhat lower than the $89 \%$ reported in two studies based on automated coding of diseases and causes of death $[14,17]$ reducing variation in the evaluation of complex situations but not necessarily resulting in higher validity of agreement [12].

The proportion of agreement varied widely depending on disease/cause of death, but was generally in line with known patterns from similar studies $[13,15,22]$ as well as from intercoder agreement studies (e.g., $[1,11])$, i.e., excellent in cancers and cerebrovascular disease and very good in respiratory and liver diseases. Discordance in less clearly defined chronic diseases may therefore be due to a large part to increased difficulty in reaching a consensus on diagnosis.

Of note, for individuals with long-lasting chronic diseases like multiple sclerosis, the immediate reason for a hospitalization is often due rather to sequelae which consequently appear as the principal hospital diagnosis. As studies from Sweden suggest, a substantial part of individual cases with discrepancies may be attributable to incomplete or inadequate transformation of the diagnostic information in the patient charts into disease assignment [31] or mistakes in death certification [16]. The fact that the logic and structure of the ICD differs from the clinical way of thinking [12] may also play a role, as well as the well-known difficulty to define a single, disease-specific, underlying cause of death in older people [6].

The proportion of agreement that was found between the underlying cause of death and hospital diagnoses was very similar to that found by Minder\&Zingg in their 1979 sample of deaths in Switzerland [22]. The only notable differences were somewhat higher agreement rates in our study for malignant neoplasms of colon, rectum and larynx, while for leukaemia and diabetes mellitus in the older study the agreement was closer.

Substantial concordance with the Minder\&Zingg study also emerged for the proportions of agreement between principal hospital diagnosis and combined primary and 

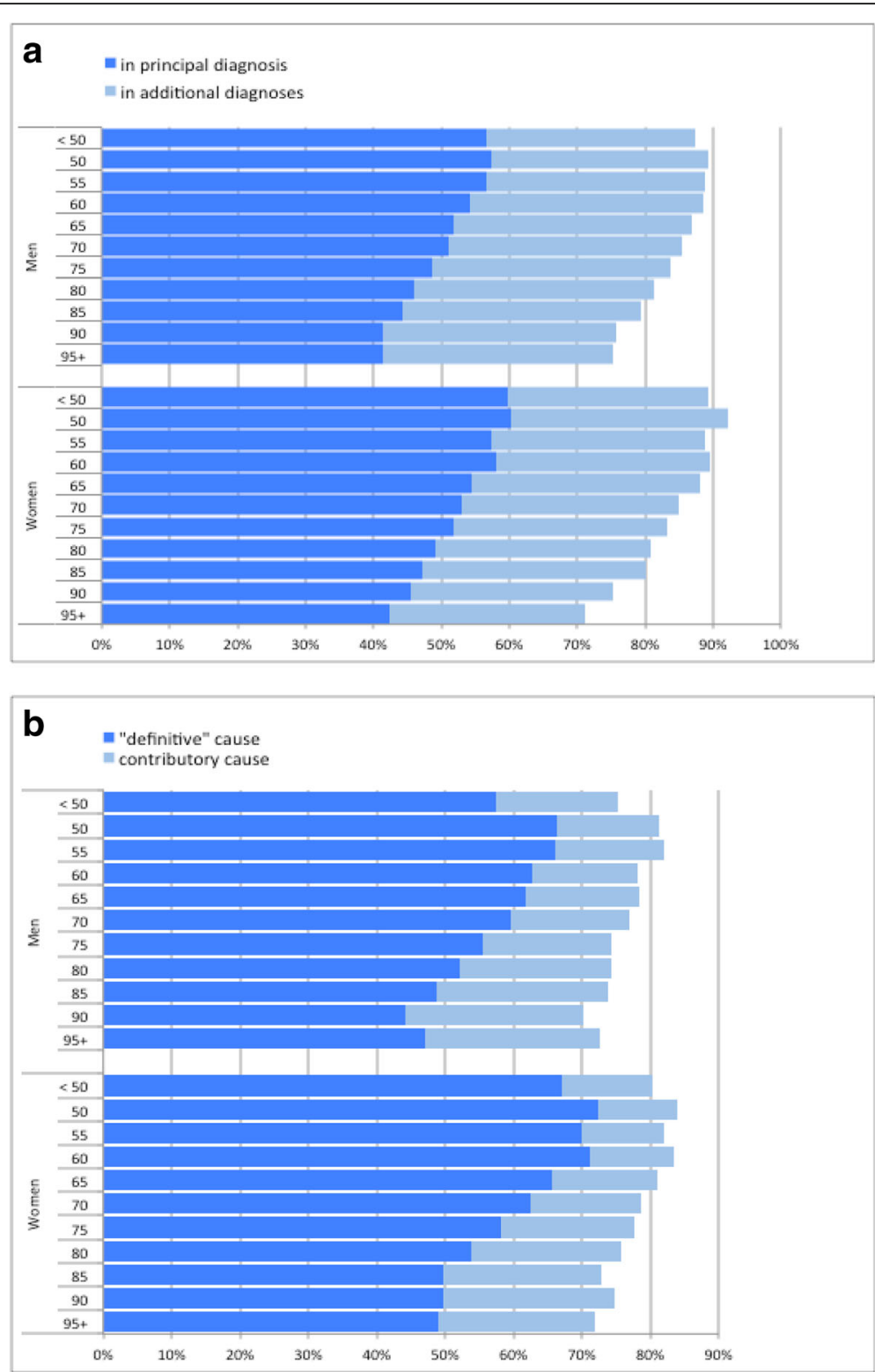

Fig. 2 Agreement of causes of death and hospital discharge diagnoses. a Agreement of underlying cause of death with diagnoses (principal or additional) registered for the terminal hospitalization, by sex and age $(N=53,605)$. b Agreement of principal hospital discharge diagnosis at death with "definitive" and contributory causes of death, by sex and age $(N=47,339)$

contributory cause of death information. The figures from our study show a closer agreement for several cancers (such as larynx, oropharynx and colon) and, most clearly, for chronic lower respiratory disease, however again less agreement in the case of diabetes mellitus. At least for cancers the proportions of agreement were also very similar as in a large Swedish study based on 1995 data [13]. This high degree of similarity of patterns also supports the notion that different evaluation of complex situations (see e.g. [32]) rather than insufficient reporting is the main reason for the variance between hospital discharge and cause of death registration.
In line with others $[1,6]$ disagreement increased with age. Our data support the notion that this may be related to an increasing number of reported diagnoses/ causes [1].

Our data do not suggest substantial variation in the individual agreement between male and female decedents, which is in line with Alpérovitch et al. [6] who however could establish associations with determinants not available in our study (history of vascular diseases, presence of incapacities, MMSE $<24,>5$ medications).

The odds ratios resulting from multiple logistic regression (Table 3) however suggest substantial variation in 
Table 3 Agreement of underlying cause of death with diagnoses (principal or additional) registered for the terminal hospitalization: multiple logistic regression $(N=50,995)$

\begin{tabular}{|c|c|c|c|}
\hline & \multicolumn{3}{|c|}{ "Definitive" cause of death found in principal or additional hospital discharge diagnoses } \\
\hline & $\mathrm{OR}$ & $95 \% \mathrm{Cl}$ & $P$-value \\
\hline \multicolumn{4}{|l|}{ Major region } \\
\hline Lake Geneva Region & 1 (ref.) & & \\
\hline Zurich & 1.28 & $1.15-1.41$ & $<0.001$ \\
\hline Espace Mittelland & 1.21 & $1.11-1.31$ & $<0.001$ \\
\hline Central & 1.13 & $1.01-1.28$ & 0.04 \\
\hline Northwest & 1.10 & $.999-1.21$ & 0.05 \\
\hline Eastern & 1.11 & $.997-1.23$ & 0.06 \\
\hline Ticino & 1.15 & $.992-1.34$ & 0.06 \\
\hline \multicolumn{4}{|c|}{ Marital status of deceased (from death certificate) } \\
\hline Single & 1 (ref.) & & \\
\hline Married & 1.28 & $1.18-1.39$ & $<0.001$ \\
\hline Widowed & 1.18 & $1.08-1.29$ & $<0.001$ \\
\hline Divorced & 1.21 & $1.09-1.35$ & $<0.001$ \\
\hline \multicolumn{4}{|c|}{ Principal language of deceased (from 2000 census) } \\
\hline German & 1 (ref.) & & \\
\hline French & .90 & $.83-.98$ & 0.01 \\
\hline Italian & 1.002 & $.89-1.12$ & 0.97 \\
\hline Other European & .91 & $.77-1.07$ & 0.26 \\
\hline Other & .73 & $.59-.90$ & $<0.01$ \\
\hline \multicolumn{4}{|c|}{ Educational level of deceased (from 2000 census) } \\
\hline Mandatory schooling & 1 (ref.) & & \\
\hline Upper secondary & 1.06 & $1.002-1.11$ & 0.04 \\
\hline Tertiary & 1.08 & $1.002-1.17$ & 0.04 \\
\hline Age of deceased (year) & .976 & $.973-.978$ & $<0.001$ \\
\hline
\end{tabular}

reporting and maybe in diagnostic practice that can not entirely be explained by age and cause of death of the deceased. Comparatively lower agreement for the less educated and those speaking a non-European language could point to a lower standard of reporting (and maybe also examination) among less advantaged patients. These findings and the substantial regional variation indicate potential for improving procedures in cause of death as well as hospital discharge reporting.

What measures could improve the quality of the MS and the cause of death statistics in Switzerland? First, the responsible authority and data owner (Swiss Federal Statistical Office, SFSO) could do much more than at present. Currently, the SFSO publishes data reports on a yearly basis and researchers can request access to individual data, but there are no published reports about data quality. Second, the regular use of data automatically helps to improve data quality, because problems become visible and can be overcome. Especially studies combining information from different data sources may promote the evaluation of corresponding strengths and limits [33]. Third, a case review based on full clinical documentation should be carried out for the areas with lower scores in this study.
For example, a sample of deaths due to diabetes could be studied in detail. The example of cancer shows that the work of cancer registries has an impact on medical documentation. An individual comparison of the cause of death statistics with the data of the cancer registries is required by law from 2020. Finally, the instruction in the scope and methods of the cause of death statistics during the basic and continuing education of physicians should be improved.

\section{Strengths and limitations}

To our best knowledge, there are only three other studies conducted in a general population and with an equivalent sample size $[13,15,17]$, two of them however analysing quite old data from 2005 [15] or even 1995 [13]. The equal consideration of both points of view, from underlying cause of death to hospital diagnoses and from principal hospital discharge diagnosis to multiple causes of death, allowing comparisons in both directions, is quite exceptional. An additional strength is the contribution of evidence whether in disease categories with not clearly distinguishable subcategories, the master or subcategories should be preferred. Compared 
to other studies reporting decreasing information on secondary causes of death for those aged over 85 [15], our data showed for those deceased under 95 no evidence of decreasing data quality with increasing age.

The study has several limitations. First, agreement rates show reproducibility rather than accuracy of information. Since both, causes of death and hospital diagnoses generally stem from the same source, they equally may be wrong [12]. High reported rates of diagnostic disagreement among medical referrals [32] call for prudence. Second, our study was restricted to individuals deceased in a hospital. Agreement between physician's diagnosis and cause of death may be substantially higher among persons who died in a hospital than among those who died elsewhere [13]. Empirical evidence is however conflicting, with studies endorsing [34] or contradicting this hypothesis [6] or showing contradictory results depending on cause of death [15]. Third, we had to exclude external causes. These were, however - closely after cancer - the category with best agreement in an autopsy study [34].

\section{Conclusion}

Depending on cause of death / hospital diagnosis, the patterns of agreement vary widely, but do not substantially differ from those found in other studies. This also and notably applies to interrater reliability studies as well as studies comparing individual data from different data sources, supporting the view that a substantial proportion of variation is due to different evaluation of complex situations by individual physicians.

The agreement rates in this study also did only slightly differ from those found almost 30 years ago, in spite of a necropsy study suggesting a significant decline of major discrepancies between 1972 and 1992 [35].

Agreement at the individual level remains limited and suggests a potential for improving data quality [14]. Even if this should not affect the reliability of population frequencies [10], the substantial regional variation (with lower agreement rates in French-speaking populations) hints at differential exploitation of available diagnosis information for cause of death statistics. Potentially worrying is the evidence for lower retrieval performance of the underlying cause of death in hospital diagnoses among socially disadvantaged groups like single, less educated, or culturally less integrated persons.

For all these reasons, studies of this kind should be regularly conducted as a quality monitoring of hospital diagnoses and causes of death.

\section{Endnotes}

${ }^{1}$ Minimal death count reached only regarding "definitive" cause of death: Malignant neoplasm of eye and adnexa; Obesity; Multiple sclerosis; Crohn's disease and ulcerative colitis; Rheumatoid arthritis and other inflammatory polyarthropathies; Hyperplasia of prostate; Congenital malformations of the circulatory system.

${ }^{2}$ Minimal death count reached only regarding principal hospital discharge diagnosis: Malnutrition; Volume depletion; Mood [affective] disorders; Neurotic, stress-related and somatoform disorders; Transient cerebral ischaemic attacks and related syndromes; Gastritis and duodenitis.

\section{Abbreviations}

AMl: Acute myocardial infarction; COPD: Chronic obstructive pulmonary disease; ICD: International Statistical Classification of Diseases and Related Health Problems; MMSE: Mini-Mental State Examination; MS: Medical Statistics of Swiss Hospitals; WHO: World Health Organization

\section{Acknowledgments}

We thank the Swiss Federal Statistical Office for providing mortality, hospital discharge and census data, and for the support, which made the construction of the Swiss National Cohort and this study possible. The members of the Swiss National Cohort Study Group are Matthias Egger (Chairman of the Executive Board), Adrian Spoerri and Marcel Zwahlen (all Bern), Milo Puhan (Chairman of the Scientific Board), Matthias Bopp (both Zurich), Martin Röösli (Basel), Michel Oris (Geneva) and Murielle Bochud (Lausanne).

\section{Funding}

UZ's work was funded by grants of the Swiss National Science Foundation (33CS30-148415, 406740-139331) and an unconditional grant of the SwissLife Jubiläumsstiftung. The funding organisations had no influence in study design, analysis or interpretation of data.

\section{Availability of data and materials}

Anonymized individual data from different data sources were used for the record linkage and the construction of the analysis files. All these data are the property of the Swiss Federal Statistical Office (SFSO) and can only be made available by legal agreements with the SFSO. However, after approval of the SNC Scientific Board, a specific SNC module contract with SFSO would allow researchers to receive analysis files for replication of the analysis. Data requests should be sent to Prof. Milo Puhan (chairman of the SNC Scientific Board, miloalan.puhan@uzh.ch). SPSS and STATA source files are available from the authors.

\section{Authors' contributions}

$\mathrm{MB}$ conceived and supervised the study and wrote the first draft of the manuscript. All authors were involved in study design, discussion and interpretation of the results. UZ carried out the record linkage and the statistical analyses. All authors repeatedly edited the manuscript and approved the final version.

\section{Ethics approval and consent to participate}

Institutional ethics approval and consent were not required since all data are anonymized. Nevertheless, ethics approval for the record linkage of hospital, cause of death and census records was given by the ethics committee of the Canton of Zurich (Amendment to Stv-Nr. 13/06).

\section{Consent for publication}

Not applicable.

Competing interests

The authors declare that they have no competing interests.

\section{Publisher's Note}

Springer Nature remains neutral with regard to jurisdictional claims in published maps and institutional affiliations. 


\section{Author details}

'Epidemiology, Biostatistics and Prevention Institute, University of Zurich, Hirschengraben 84, CH-8001 Zürich, Switzerland. ${ }^{2}$ Swiss Federal Statistical Office, Espace de l'Europe 10, 2010 Neuchâtel, Switzerland.

Received: 2 March 2018 Accepted: 28 January 2019

Published online: 01 March 2019

\section{References}

1. Lu TH, Lee MC, Chou MC. Accuracy of cause-of-death coding in Taiwan: types of miscoding and effects on mortality statistics. Int J Epidemiol. 2000; 29:336-43.

2. Rampatige R, Mikkelsen L, Hernandez B, Riley I, Lopez AD. Systematic review of statistics on causes of deaths in hospitals: strengthening the evidence for policy-makers. Bull World Health Organ. 2014;92:807-16.

3. GBD 2015 Healthcare Access and Quality Collaborators. Healthcare access and quality index based on mortality from causes amenable to personal health care in 195 countries and territories, 1990-2015: a novel analysis from the global burden of disease study 2015. Lancet. 2017;390:231-66.

4. Alderson M. Mortality, morbidity and health statistics. New York: Stockton Press; 1988.

5. Mahapatra P, Shibuya K, Lopez AD, Coullare F, Notzon FC, Rao C, Szreter S. Civil registration systems and vital statistics: successes and missed opportunities. Lancet. 2007;370:1653-63.

6. Alpérovitch $A$, Bertrand $M$, Jougla $E$, Vidal JS, Ducimetière $P$, Helmer $C$, et al. Do we really know the cause of death of the very old? Comparison between official mortality statistics and cohort study classification. Eur J Epidemiol. 2009;24:669-75.

7. Klug SJ, Bardehle D, Ressing M, Schmidtmann I, Blettner M. Vergleich von ICD-Kodierungen zwischen Mortalitätsstatistik und studieninterner retrospektiver Nachkodierung. Gesundheitswesen. 2009;71:220-5.

8. Kelson $\mathrm{M}$, Farebrother $\mathrm{M}$. The effect on inaccuracies in death certification and coding practices in the European economic community (EEC) on international cancer mortality statistics. Int J Epidemiol. 1987;16:411-4.

9. Percy C, Muir C. The international comparability of cancer mortality data. Results of an international death certificate study. Am J Epidemiol. 1989;129: 934-45.

10. Winkler V, Ott JJ, Becher H. Reliability of coding causes of death with ICD-10 in Germany. Int J Public Health. 2010;55:43-8.

11. Harteloh P, de Bruin K, Kardaun J. The reliability of cause-of-death coding in the Netherlands. Eur J Epidemiol. 2010;25:531-8.

12. Surjan G. Questions on validity of international classification of diseasescoded diagnoses. Int J Medical Inform. 1999;54:77-95.

13. Johansson LA, Westerling R. Comparing Swedish hospital discharge records with death certificates: implications for mortality statistics. Int J Epidemiol. 2000;29:495-502.

14. Johansson LA, Westerling R. Comparing hospital discharge records with death certificates: can the differences be explained? J Epidemiol Community Health. 2002;56:301-8.

15. Klijs B, Nusselder WJ, Mackenbach JP. Nationwide individual record linkage study showed poor agreement of causes of death and hospital diagnoses at individual level but reasonable agreement at population level. J Clin Epidemiol. 2014;67:160-8.

16. Johansson LA, Biörkenstam C, Westerling R. Unexplained differences between hospital and mortality data indicated mistakes in death certification: an investigation of 1,094 deaths in Sweden during 1995. J Clin Epidemiol. 2009;62:1202-9.

17. Lamarche-Vadel A, Pavillon G, Aouba A, Johansson LA, Meyer L, Jougla $E_{\text {, }}$ Rey G. Automated comparison of last hospital main diagnosis and underlying cause of death ICD10 codes, France, 2008-2009. BMC Med Inform Decis Mak. 2014;14:44.

18. Bundesamt für Statistik (BFS). Cause of death and stillbirth statistics. Fact sheet. Version 17.10.2016. available under: https:/www.bfs.admin.ch/bfs/en/home/ statistics/health/surveys/ecod.assetdetail.7037.html. Accessed 12 Jan 2018.

19. Mathers CD, Ma Fat D, Inoue M, Rao C, Lopez AD. Counting the dead and what they died from: an assessment of the global status of cause of death data. Bull WHO. 2005;83:171-7.

20. GBD 2016 Causes of Death Collaborators. Global, regional, and national agesex specific mortality for 264 causes of death, 1980-2016: a systematic analysis for the global burden of disease study 2016. Lancet. 2017;390:1151-210.
21. Bundesamt für Statistik (BFS). Krebssterblichkeit: Qualität der Daten in der Schweiz. Beiträge zur schweizerischen Statistik, Heft 125. Bern: BFS; 1984.

22. Minder CE, Zingg W. Die Sterblichkeitsstatistik in der Schweiz Datenqualität der Todesursachen und der Berufsbezeichnungen. Amtliche Statistik der Schweiz 155. Bern: Bundesamt für Statistik; 1989.

23. Lutz JM, Pury P, Fioretta G, Raymond L. The impact of coding process on observed cancer mortality trends in Switzerland. Eur I Cancer Prev. 2004;13:77-81.

24. Roy E. Todesursachen 1970-2009: Entwicklung von Generation zu Generation - Methode. Neuchâtel: Bundesamt für Statistik; 2014.

25. World Health Organization. International statistical classification of diseases and related health problems. Tenth revision, vol. Il. 2010th ed. Geneva: WHO; 2011

26. Bundesamt für Statistik (BFS). Medizinische Statistik der Krankenhäuser. Version 17.10.2016. available under: https:/www.bfs.admin.ch/bfs/de/home/statistiken/ gesundheit/erhebungen/ms.assetdetail.7369.html. Accessed 12 Jan 2018

27. Bundesamt für Statistik (BFS). Der Datenschutz in der Medizinischen Statistik / La protection des données dans la statistique médicale. Version 9.1.2013. available under: https://www.bfs.admin.ch/bfs/de/home/statistiken/ gesundheit/erhebungen/ms.assetdetail.230439.html. Accessed 12 Jan 2018.

28. Bopp M, Spoerri A, Zwahlen M, Gutzwiller F, Paccaud F, Braun-Fahrländer C, et al. Cohort profile: the Swiss National Cohort - a longitudinal study of 6.8 million people. Int J Epidemiol. 2009;38:379-84.

29. Zellweger U, Bopp M. Record Linkage der Todesfälle in der Medizinischen Statistik der Krankenhäuser und der Statistik der Sozialmedizinischen Institutionen 2002-2012 mit der Swiss National Cohort (Swiss National Cohort Report Nr. 9). Forschung und Dokumentation 38, Institut für Epidemiologie, Biostatistik und Prävention der Universität Zürich; 2017.

30. Ravona-Springer R, Davidson M, Noy S. Is the distinction between Alzheimer's disease and vascular dementia possible and relevant? Dialogues Clin Neurosci. 2003:5(1):7-15.

31. Ludvigsson JF, Andersson E, Ekbom A, Feychting M, Kim JL, Reuterwall C, et al. External review and validation of the Swedish national inpatient register. BMC Public Health. 2011:11:450

32. Van Such M, Lohr R, Beckman T, Naessens JM. Extent of diagnostic agreement among medical referrals. J Evol Clin Pract. 2017;23:870-4.

33. Zellweger U, Bopp M, Holzer BH, Djalali S, Kaplan V. Prevalence of chronic medical conditions in Switzerland: improving estimates validity by combining imperfect data sources. BMC Public Health. 2014;14:1157.

34. Modelmog D, Rahlenbeck S, Trichopoulos D. Accuracy of death certificates: a population-based, complete-coverage, one-year autopsy study in East Germany. Cancer Causes Control. 1992;3:541-6.

35. Sonderegger-Iseli K, Burger S, Muntwyler J, Salomon F. Diagnostic errors in three medical eras: a necropsy study. Lancet. 2000;355:2027-31.

Ready to submit your research? Choose BMC and benefit from:

- fast, convenient online submission

- thorough peer review by experienced researchers in your field

- rapid publication on acceptance

- support for research data, including large and complex data types

- gold Open Access which fosters wider collaboration and increased citations

- maximum visibility for your research: over $100 \mathrm{M}$ website views per year

At $\mathrm{BMC}$, research is always in progress.

Learn more biomedcentral.com/submissions 